\title{
Case Report: A Troublesome Ophthalmic Artery Aneurysm
}

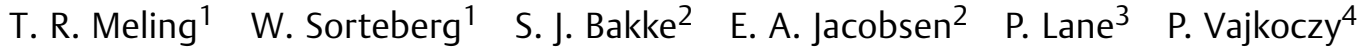 \\ ${ }^{1}$ Department of Neurosurgery, Oslo University Hospital, \\ Rikshospitalet, Oslo, Norway \\ ${ }^{2}$ Department of Neuroradiology, Oslo University Hospital, \\ Rikshospitalet, Oslo, Norway \\ ${ }^{3}$ Department of Ophthalmology, Oslo University Hospital, Ullevaal, \\ Oslo, Norway \\ ${ }^{4}$ Department of Neurosurgery, Charité Universitätsmedizin \\ Berlin, Germany \\ J Neurol Surg Rep 2014;75:e230-e235.

\begin{abstract}
Address for correspondence Torstein R. Meling, MD, PhD, Department of Neurosurgery, Oslo University Hospital, Rikshospitalet, 0027 Oslo, Norway (e-mail: torsteinrmeling@mailcity.com).
\end{abstract}

\begin{abstract}
\section{Keywords}

- ophthalmic artery aneurysm

- endovascular treatment

- neurovascular surgery

- complications

Objective and Importance When treating large unruptured ophthalmic artery (OA) aneurysms causing progressive blindness, surgical clipping is still the preferred method because aneurysm sac decompression may relieve optic nerve compression. However, endovascular treatment of $\mathrm{OA}$ aneurysms has made important progress with the introduction of stents. Although this development is welcomed, it also makes the choice of treatment strategy less straightforward than in the past, with the potential of missteps.

Clinical Presentation A 56-year-old woman presented with a long history of progressive unilateral visual loss and magnetic resonance imaging showing a 20 -mm left-sided OA aneurysm.

Intervention Because of her long history of very poor visual acuity, we considered her left eye to be irredeemable and opted for endovascular therapy. The OA aneurysms was treated with stent and coils but continued to grow, threatening the contralateral eye. Because she failed internal carotid artery (ICA) balloon test occlusion, we performed a high-flow extracranial-intracranial bypass with proximal ICA occlusion in the neck. However, aneurysm growth continued due to persistent circulation through reversed blood flow in distal ICA down to the OA and the cavernous portion of the ICA. Due to progressive loss of her right eye vision, we surgically occluded the ICA proximal to the posterior communicating artery and excised the coiled, now giant, OA aneurysm. This improved her right eye vision, but her left eye was permanently blind.

Conclusion This case report illustrates complications of the endovascular and surgical treatment of a large unruptured OA aneurysm.
\end{abstract}

\section{Background}

The ophthalmic segment of the internal carotid artery (ICA), running from the distal dural ring to the posterior communi- cating artery (PCOM), can give rise to aneurysms. ${ }^{1}$ The three subtypes are the superiorly pointing aneurysms originating at the ophthalmic artery (i.e., ophthalmic artery $[\mathrm{OA}]$ aneurysms), the medially pointing aneurysms originating from the received

March 2, 2014

accepted after revision

June 9, 2014

published online

August 21, 2014
DOI http://dx.doi.org/

10.1055/s-0034-1387187. ISSN 2193-6358. (c) 2014 Georg Thieme Verlag KG Stuttgart - New York
License terms

(1) $\Theta \circledast$ 
superior hypophyseal trunk, and aneurysms originating from a perforator-free part of the ICA, the so-called atypical or blister ICA aneurysms. ${ }^{2}$

The incidence of OA aneurysms is somewhere between $0.5 \%$ and $11 \%$ of all intracranial aneurysms. ${ }^{3,4}$ Unruptured large OA aneurysms frequently present with gradual loss of vision. The goal of their treatment is then twofold: to exclude the aneurysm from the circulation and to preserve or restore visual function. Treatment of OA aneurysms can be surgical or endovascular, depending on the mode of presentation, aneurysm geometrics and size, as well as the patients medical condition. ${ }^{5}$ In the past, intracranial aneurysm repair was exclusively surgical, ${ }^{4}$ and in large unruptured OA aneurysms, clipping is still often the preferred method because surgical decompression of the aneurysm sac may lend the optic nerve a better prognosis. ${ }^{6,7}$ However, surgery of OA aneurysms carry inherent risks such as stroke, ${ }^{8}$ hemorrhage, ${ }^{9}$ or visual loss. ${ }^{10-12}$

Since its introduction in $1991,{ }^{13}$ endovascular aneurysm repair has grown in popularity and versatility. $8,14,15$ With the introduction of stents, ${ }^{16,17}$ endovascular treatment of $\mathrm{OA}$ aneurysms has made important progress. Although this
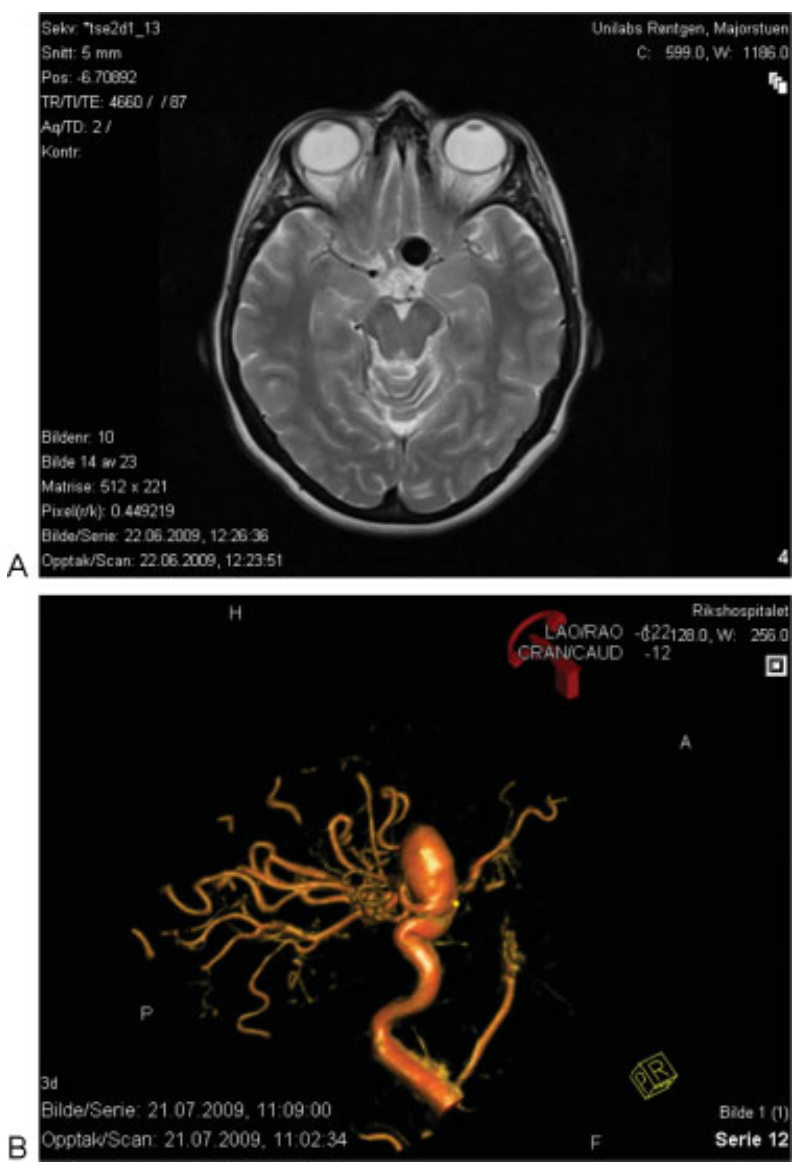

Fig. 1 Magnetic resonance imaging (MRI) of a 56-year-old righthanded woman who presented with a 4-month history of retro-orbital headache and progressive visual loss demonstrating a left-sided ophthalmic artery aneurysm $20 \times 12 \times 13 \mathrm{~mm}$ in diameter. (A) Axial T2-weighted MRI demonstrating the relationship to the left optic nerve. (B) Three-dimensional digital subtraction angiography demonstrating the aneurysm sac. development is welcomed, it also makes the choice of treatment strategy less straightforward than in the past.

In this report, we present a patient with a troublesome unruptured OA aneurysm and some lessons learned.

\section{Case Report}

\section{Clinical Presentation}

A 56-year-old right-handed woman presented with a 4-month history of retro-orbital headache and progressive decline in visual acuity oculus sinister (OS). Her ophthalmologist (P.L.) found only perception of light OS and normal visual acuity oculus dexter (OD). Magnetic resonance imaging (MRI) detected a left-sided OA aneurysm $20 \times 12 \times 13 \mathrm{~mm}$ in diameter (-Fig. 1).

Because of her long history of very poor visual acuity, we considered her left eye to be irredeemable. Because the aneurysm had a wide neck and was of moderate size, endovascular treatment was chosen. The treatment plan was first to place a regular stent within the ICA, running from proximal to the OA to distal to the PCOM artery, with a second semipermeable stent inside the first stent in the aneurysm orifice area to enhance aneurysm thrombosis. Following 1 week of treatment with Plavix and aspirin preceding the endovascular procedure, a LEO (Balt Extrusion, Montmorency, France) $4.5 \mathrm{~mm} \times 40 \mathrm{~mm}$

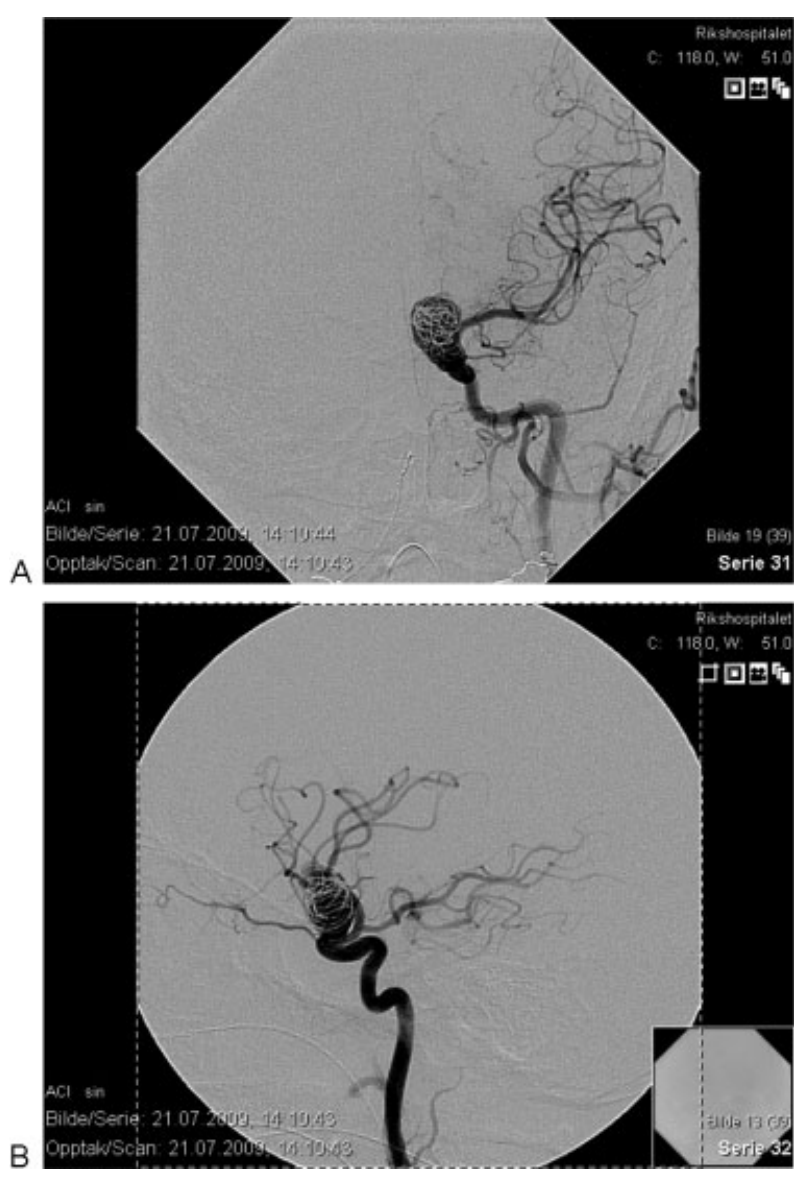

Fig. 2 Digital subtraction angiography after a stent was placed in the interior carotid artery and the aneurysm sac coiled using three matrix coils. (A) Anteroposterior view. (B) Lateral view. 
stent was placed in the ICA (S. J. B. and E. A. J.). Attempts to place additional stents, however, were unsuccessful. To promote aneurysm thrombosis, three Matrix coils (Boston Scientific, Fremont, California, United States), of $24 \mathrm{~mm} \times 40 \mathrm{~cm}$, $30 \mathrm{~mm} \times 16 \mathrm{~cm}$, and $14 \mathrm{~mm} \times 30 \mathrm{~cm}$, respectively, were put into the aneurysm sac (-Fig. 2). This led to stagnation of the contrast media in the aneurysm sac, but because of the optic nerve compression, the aneurysm was filled loosely so as not to cause further optic chiasm compression.

After the procedure, the patient woke up with an expressive dysphasia and a right-sided hemiparesis. MRI demonstrated several punctate lesions in the left parieto-occipital region secondary to emboli and perfusion MRI showed a small hypoperfusion in the left lentiform nucleus region. She subsequently recovered completely from her neurologic deficits. Her visual acuity improved to perception of hand movement ad ocolum OS and acuity OD remained at 1.0.

Over the following months, the aneurysm continued to grow, measuring $22 \times 13 \times 14 \mathrm{~mm}$ (-Fig. 3 ). It now caused significant compression of both optic nerves, and her ophthalmologist recorded a reduction of visual acuity to $0.8 \mathrm{OD}$ and an upper quadrant anopia. A course of prednisolone $20 \mathrm{mg}$ twice daily was tried for 5 days without effect.

Six months after her presentation, her visual acuity remained at light perception OS and 0.8 OD with an upper
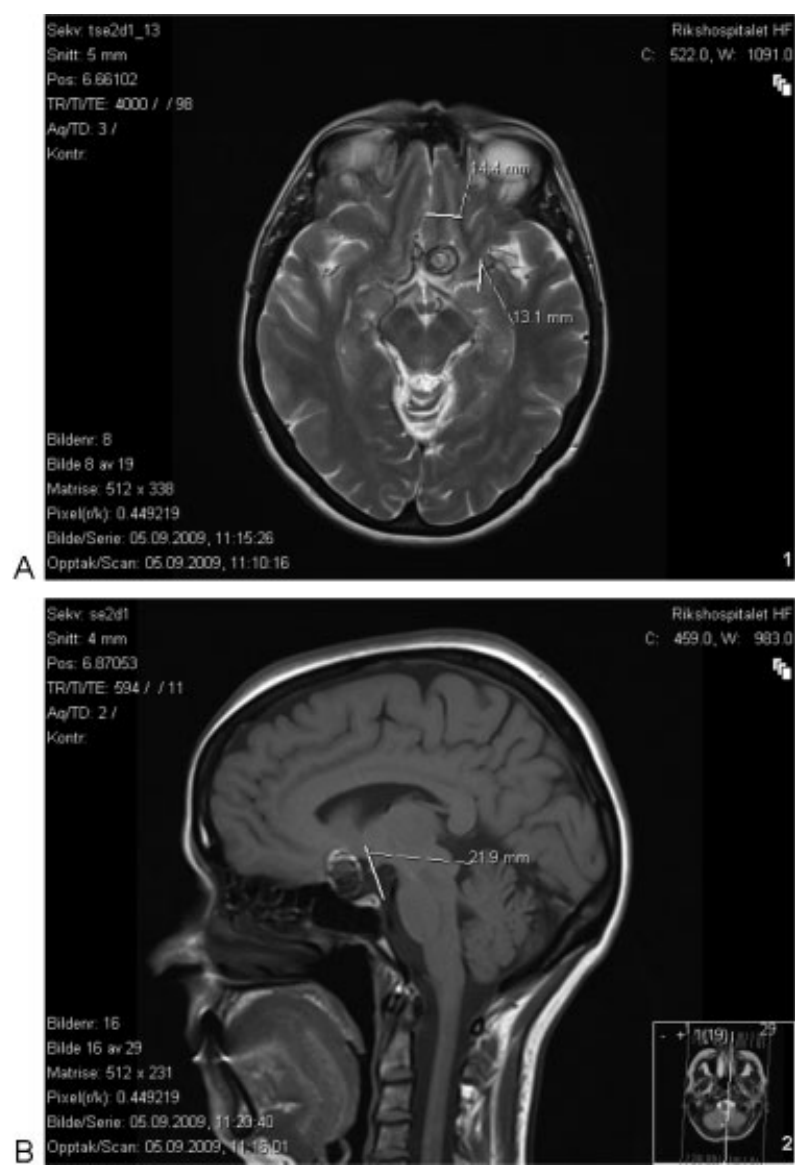

Fig. 3 The aneurysm continued to grow, measuring $22 \times 13 \times 14 \mathrm{~mm}$ 2 months post-coiling. (A) Axial T2-weighted magnetic resonance imaging (MRI). (B) Sagittal T1-weighted MRI. quadrant anopia. A digital subtraction angiography (DSA) demonstrated coil compaction and further aneurysm growth. The patient failed an ICA balloon test occlusion (W.S.O.) and was therefore referred to high-flow extracranial-intracranial (EC-IC) artery bypass grafting in Berlin, Germany. Preoperatively, her visual acuity OD was down to 0.7 with an upper quadrant anopia, whereas OS remained at light perception. She underwent a high-flow venous graft bypass between the left external carotid artery and the left middle cerebral artery (P.V. and T.R.M.) (-Fig. 4). Because of the combined effects of stent within the ICA and the large coil mass in the aneurysm, it was difficult to put an occluding clip on the ICA just distal to the OA take-off, and the ICA was therefore occluded proximally in the neck.

Postoperatively, she had expressive dysphasia, right-sided hemiparesis, and short-term memory loss. She was also completely blind in the left eye. Postoperative T1-weighted MRI demonstrated some encephalomalacia with peri-Sylvian cortical laminar necrosis in the temporal and frontal lobes (-Fig.5). Over the next months she recovered well from these neurologic deficits, with the exception of blindness OS.

Contrary to what we anticipated, the aneurysm continued to expand $(27 \times 19 \times 20 \mathrm{~mm})$; her right eye visual acuity
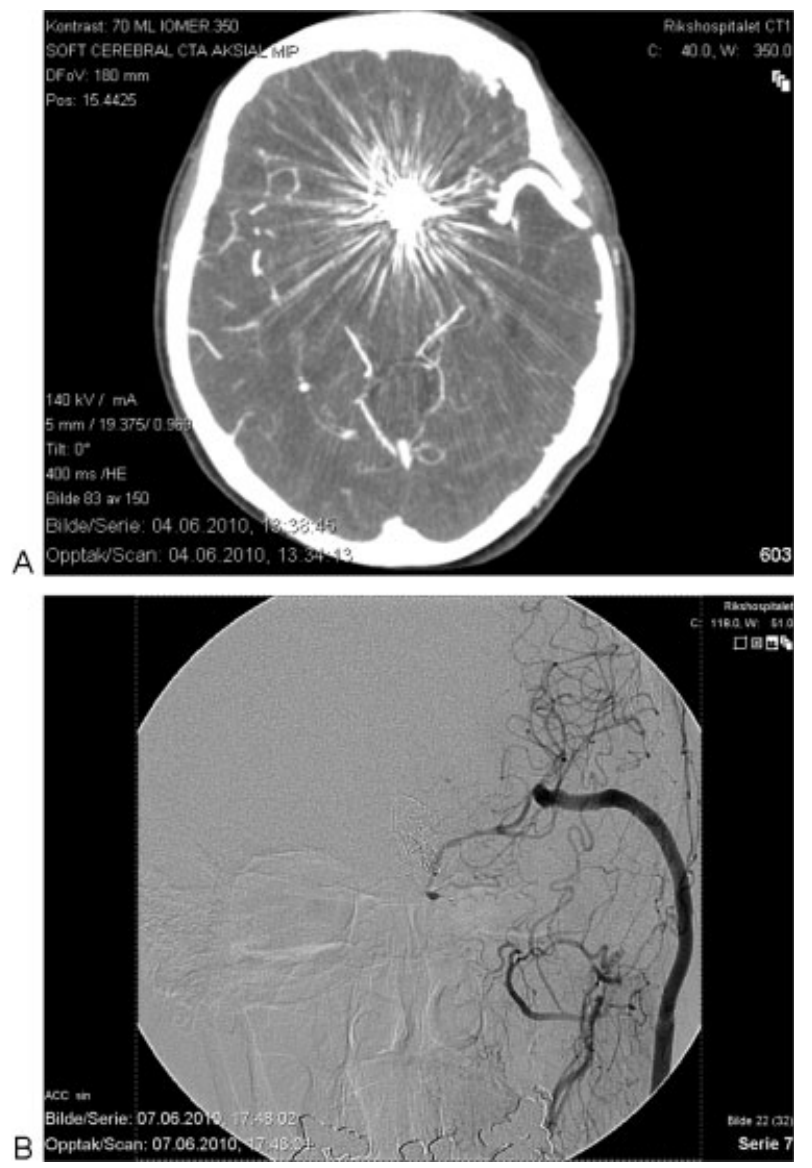

Fig. 4 The patient underwent a high-flow venous graft bypass between the left external carotid artery and the middle cerebral artery (MCA). The internal carotid artery was occluded proximally in the neck. (A) Axial computed tomography angiography demonstrating the patent graft to MCA and coil artifacts. (B) Digital subtraction angiography anteroposterior view demonstrating filling of the extracranialintracranial bypass. 

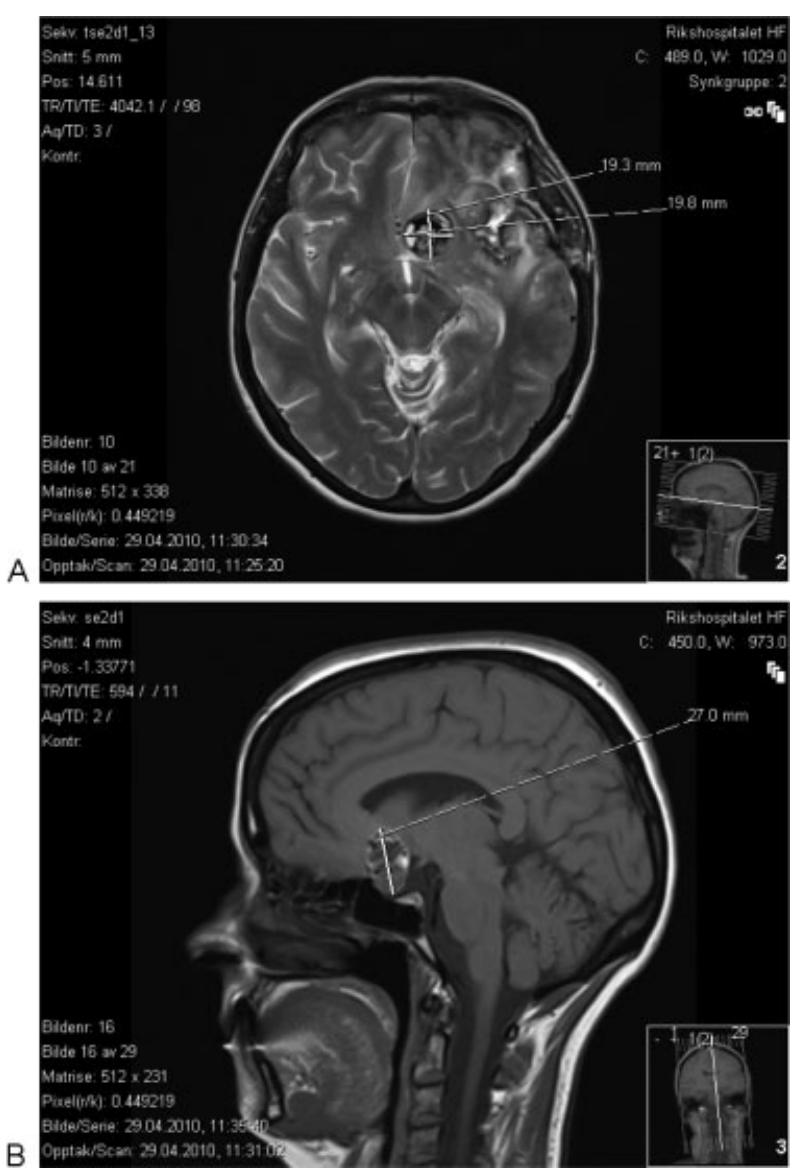

Fig. 5 Postoperative fluid attenuated inversion recovery magnetic resonance imaging demonstrates some encephalomalacia with periSylvian cortical laminar necrosis. She became completely blind in her left eye.

decreased dramatically to 0.3 a month after the surgery. A DSA demonstrated good flow through the bypass, retrograde filling of the distal ICA, antegrade filling of the OA, some filling in the cavernous portion of the ICA, and some filling in the bottom of the aneurysm ( - Fig. 6 ), the latter finding explaining the continued aneurysm growth.

Because of progressive visual field defect and acuity loss OD, the patient was operated again a year after her initial presentation via a $30 \times 25 \mathrm{~mm}$ supraorbital craniotomy (T.R.M.). The stented ICA was "crushed" using a DeBakey forceps to fit a clip across the ICA proximal to the PCOM. The previously coiled giant aneurysm was thereafter excised (-Fig. 7), and the optic chiasm and both optic nerves were decompressed. The patient made an uneventful recovery, and the surgery led to a significant improvement in visual acuity OD to 0.7 . Her left eye remained amaurotic.

\section{Discussion}

Major neurologic deficits after treatment of giant intracranial aneurysms occur in $\sim 10 \%$ of patients. ${ }^{18-22}$ With paraclinoid giant aneurysms, visual deterioration after treatment is observed in up to $17 \%$ of patients. ${ }^{19,20}$ Although surgical clipping is often the preferred treatment for aneurysms
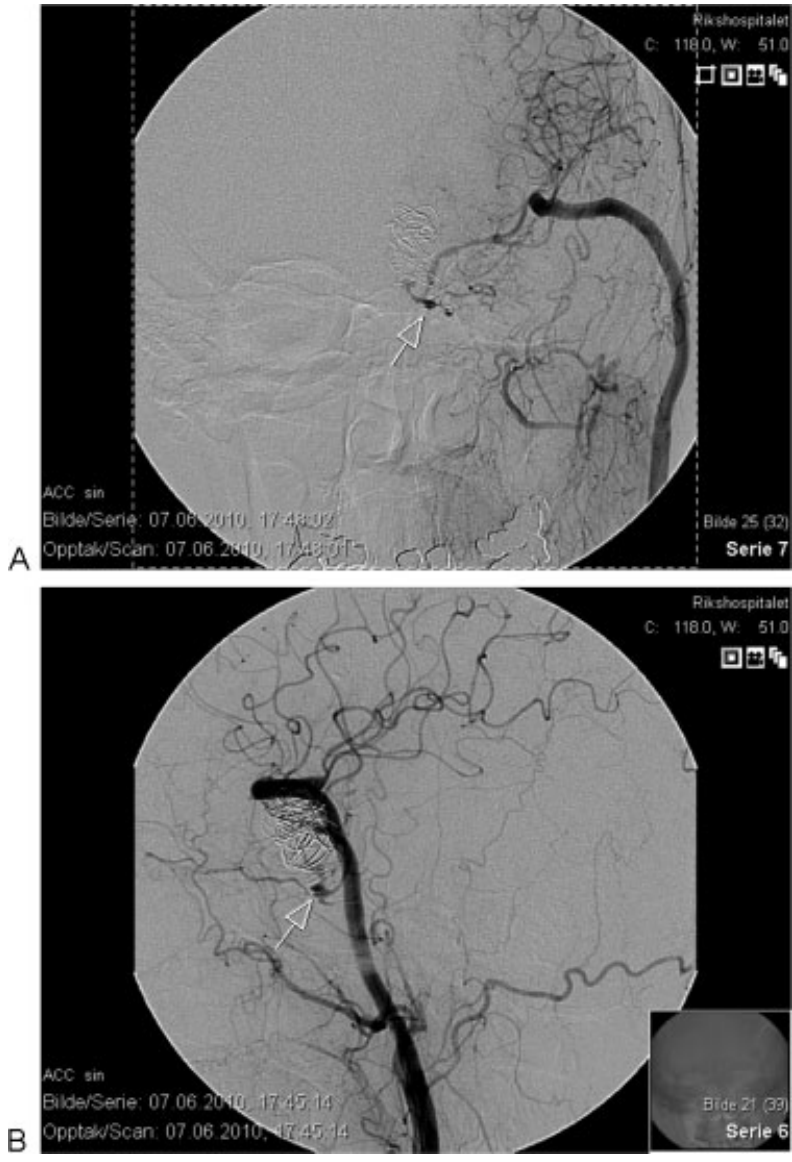

Fig. 6 The aneurysm continued to expand, severely compromising vision of her right eye. Digital subtraction angiography demonstrates good bypass flow, with retrograde filling of the distal internal carotid artery (ICA), antegrade filling of the ophthalmic artery, and some filling in the cavernous portion of the ICA. There is also some filling of the caudal part of the aneurysm (arrow), the latter finding explaining the continued aneurysm growth. (A) Anteroposterior view. (B) Lateral view.

causing cranial nerve deficits, ${ }^{6,7}$ in cases of giant paraclinoid ICA aneurysms, it may not be feasible in $>60 \%$ of cases. $^{18,20-22}$ Surgery on OA aneurysms is technically demanding because these aneurysms are often large and may extend into the cavernous sinus. ${ }^{21-26}$ Thus they are challenging even for the most experienced of neurosurgeons. Over the years, these aneurysms have therefore been treated by common carotid artery ligation, ${ }^{20-22,27,28}$ ICA occlusion, ${ }^{18-20,22,29,30}$ proximal vessel ligation with EC-IC bypass, ${ }^{18-20,22}$ trapping, ${ }^{18,19,31}$ intra-aneurysmal balloon occlusion, ${ }^{32,33}$ coiling, $^{34-36}$ or by stenting. ${ }^{37}$ However, because visual deterioration after coil embolization of $\mathrm{OA}$ aneurysms has been reported in as many as a third of the patients, ${ }^{14}$ the decision whether to clip or coil is often difficult.

In the present case, the endovascular treatment plan was to first place a regular stent in the ICA from the OA to the PCOM, with a second semipermeable stent inside the first stent in the aneurysm orifice area. Retrospectively, upon failing to place the semipermeable stent, we should have discontinued the endovascular procedure because the 


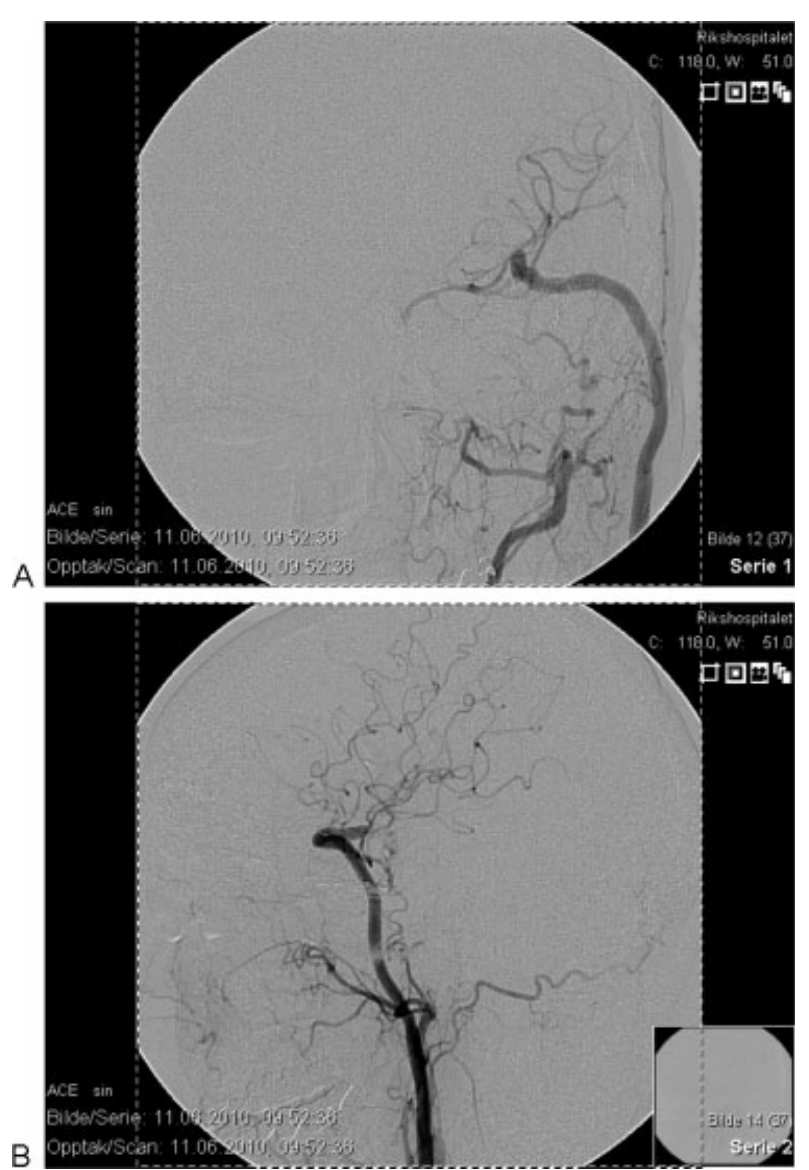

Fig. 7 The patient was reoperated via a $30 \times 25 \mathrm{~mm}$ supraorbital craniotomy, so as not to compromise the bypass. The stented internal carotid artery (ICA) was "crushed" using a DeBakey forceps to fit a clip across the ICA proximal to the posterior communicating artery, and the coiled giant aneurysm was excised, thereby decompressing the optic chiasm and optic nerves. Surgery led to a significant improvement in visual acuity on the right side; the left remained amaurotic. (A) Anteroposterior view. (B) Lateral view.

subsequent aneurysm coiling would not make the aneurysm shrink and would make aneurysm surgery at a later stage considerably more difficult.

Given a situation with a large and growing coiled aneurysm and with a failed balloon test occlusion (BTO), we opted for a high-flow EC-IC bypass followed by therapeutic ICA closure because ICA occlusion, with or without EC-IC bypass, is a good therapeutic option when treating giant ICA aneurysms. ${ }^{29,38-44}$ However, it proved difficult to put an occluding clip on the ICA just distal to the OA take-off due to the combined effects of the stent within the ICA and the large coil mass within the aneurysm. Furthermore, the PCOM was also not in sight due to the previously mentioned limiting structures, but also because of the high-flow vein graft in the surgical field. Consequently, the ICA was occluded proximally in the neck. Retrospectively, after finishing the bypass and realizing that the intracranial ICA closure was impossible, we should have left the ICA open and closed this vessel off endovascularly by placing coils at the origin of the OA/ aneurysm because it is known that proximal ICA occlusion does not fully prevent subsequent hemorrhage or necessarily prevent aneurysm enlargement. ${ }^{10,20,21,38,41,45,46}$ A more distal ICA closure would have eliminated blood flow in the ICA below the PCOM and triggered thrombosis and shrinkage of the noncoiled portion of the aneurysm.

In retrospect, our patient should have been treated initially with surgical clipping. It is difficult to tidy up the mess, as it were, if you start out wrong. Given the chance again, we would have followed our usual game plan when treating patients with large unruptured OA aneurysms: If there is reduced visual acuity and no or moderate thrombus material in the aneurysm, we opt for surgical clipping via a lateral supraorbital craniotomy with extradural clinoidectomy for proximal control of the ophthalmic ICA segment, ${ }^{47}$ aneurysm dissection, suction/decompression of the aneurysm (either direct after temporary trapping or ad modum Hunt Batjer with exposure of the ICA in the neck ${ }^{48}$ ), and aneurysm clipping. If there is a large thrombotic mass in the aneurysm, with or without reduced visual acuity, we generally manage our patients with semipermeable (flow diversion) stents or therapeutic ICA closure with or without a high-flow excimer laser-assisted nonocclusive anastomosis (ELANA) bypass for flow replacement, ${ }^{43}$ depending on the BTO tolerance. ${ }^{44}$

\section{References}

1 Peris-Celda M, Da Roz L, Monroy-Sosa A, Morishita T, Rhoton AL Jr. Surgical anatomy of endoscope-assisted approaches to common aneurysm sites. Neurosurgery 2014;10(Suppl 1):121-144; discussion 144

2 Meling TR, Sorteberg A, Bakke SJ, Slettebø H, Hernesniemi J, Sorteberg W. Blood blister-like aneurysms of the internal carotid artery trunk causing subarachnoid hemorrhage: treatment and outcome. J Neurosurg 2008;108(4):662-671

3 Day AL. Aneurysms of the ophthalmic segment. A clinical and anatomical analysis. J Neurosurg 1990;72(5):677-691

4 Yasargil MG, Gasser JC, Hodosh RM, Rankin TV. Carotid-ophthalmic aneurysms: direct microsurgical approach. Surg Neurol 1977; 8(3):155-165

5 Debrun GM, Aletich VA, Kehrli P, Misra M, Ausman JI, Charbel F. Selection of cerebral aneurysms for treatment using Guglielmi detachable coils: the preliminary University of Illinois at Chicago experience. Neurosurgery 1998;43(6):1281-1295; discussion 1296-1297

6 de Oliveira JG, Borba LA, Rassi-Neto A, et al. Intracranial aneurysms presenting with mass effect over the anterior optic pathways: neurosurgical management and outcomes. Neurosurg Focus 2009; 26(5):E3

7 Tawk RG, Villalobos HJ, Levy EI, Hopkins LN. Surgical decompression and coil removal for the recovery of vision after coiling and proximal occlusion of a clinoidal segment aneurysm: technical case report. Neurosurgery 2006;58(6):E1217; discussion E1217

8 Fulkerson DH, Horner TG, Payner TD, et al. Results, outcomes, and follow-up of remnants in the treatment of ophthalmic aneurysms: a 16-year experience of a combined neurosurgical and endovascular team. Neurosurgery 2009;64(2):218-229; discussion 229-230

9 Korosue K, Heros RC. "Subclinoid" carotid aneurysm with erosion of the anterior clinoid process and fatal intraoperative rupture. Neurosurgery 1992;31(2):356-359; discussion 359-360

10 Kumon Y, Sakaki S, Kohno K, Ohta S, Ohue S, Oka Y. Asymptomatic unruptured carotid-ophthalmic artery aneurysms: angiographical differentiation of each type, operative results, and indications. Surg Neurol 1997;48(5):465-472 
11 De Jesús O, Sekhar LN, Riedel CJ. Clinoid and paraclinoid aneurysms: surgical anatomy, operative techniques, and outcome. Surg Neurol 1999;51(5):477-487; discussion 487-488

12 Fries G, Perneczky A, van Lindert E, Bahadori-Mortasawi F. Contralateral and ipsilateral microsurgical approaches to carotidophthalmic aneurysms. Neurosurgery 1997;41(2):333-342; discussion 342-343

13 Guglielmi G. History of the genesis of detachable coils. A review. J Neurosurg 2009;111(1):1-8

14 Heran NS, Song JK, Kupersmith MJ, et al. Large ophthalmic segment aneurysms with anterior optic pathway compression: assessment of anatomical and visual outcomes after endosaccular coil therapy. J Neurosurg 2007;106(6):968-975

15 Park HK, Horowitz M, Jungreis C, et al. Endovascular treatment of paraclinoid aneurysms: experience with 73 patients. Neurosurgery 2003;53(1):14-23; discussion 24

16 Urbach $\mathrm{H}$, Tschampa $\mathrm{H}$, Kovács $\mathrm{A}$, Greschus S, Schramm J. The enterprise stent for the treatment of intracranial aneurysms: stenting strategies. Klin Neuroradiol 2009;19(3):197-203

17 Mericle RA, Lanzino G, Wakhloo AK, Guterman LR, Hopkins LN. Stenting and secondary coiling of intracranial internal carotid artery aneurysm: technical case report. Neurosurgery 1998;43(5): $1229-1234$

18 Drake CG. Giant intracranial aneurysms: experience with surgical treatment in 174 patients. Clin Neurosurg 1979;26:12-95

19 Ferguson GG, Drake CG. Carotid-ophthalmic aneurysms: visual abnormalities in 32 patients and the results of treatment. Surg Neurol 1981;16(1):1-8

20 Heros RC, Nelson PB, Ojemann RG, Crowell RM, DeBrun G. Large and giant paraclinoid aneurysms: surgical techniques, complications, and results. Neurosurgery 1983;12(2):153-163

21 Hosobuchi Y. Direct surgical treatment of giant intracranial aneurysms. J Neurosurg 1979;51(6):743-756

22 Sundt TM Jr, Piepgras DG. Surgical approach to giant intracranial aneurysms. Operative experience with 80 cases. J Neurosurg 1979; 51(6):731-742

23 Almeida GM, Shibata MK, Bianco E. Carotid-ophthalmic aneurysms. Surg Neurol 1976;5(1):41-45

24 Kattner KA, Bailes J, Fukushima T. Direct surgical management of large bulbous and giant aneurysms involving the paraclinoid segment of the internal carotid artery: report of 29 cases. Surg Neurol 1998;49(5):471-480

25 Nutik SL. Ventral paraclinoid carotid aneurysms. J Neurosurg 1988;69(3):340-344

26 Nutik S. Carotid paraclinoid aneurysms with intradural origin and intracavernous location. J Neurosurg 1978;48(4):526-533

27 Giannotta SL, McGillicuddy JE, Kindt GW. Gradual carotid artery occlusion in the treatment of inaccessible internal carotid artery aneurysms. Neurosurgery 1979;5(4):417-421

28 Swearingen B, Heros RC. Common carotid occlusion for unclippable carotid aneurysms: an old but still effective operation. Neurosurgery 1987;21(3):288-295

29 Fox AJ, Viñuela F, Pelz DM, et al. Use of detachable balloons for proximal artery occlusion in the treatment of unclippable cerebral aneurysms. J Neurosurg 1987;66(1):40-46

30 Hodes JE, Aymard A, Gobin YP, et al. Endovascular occlusion of intracranial vessels for curative treatment of unclippable aneurysms: report of 16 cases. J Neurosurg 1991;75(5):694-701

31 Fox JL. Microsurgical treatment of ventral (paraclinoid) internal carotid artery aneurysms. Neurosurgery 1988;22(1 Pt 1):32-39

32 Higashida RT, Halbach VV, Barnwell SL, et al. Treatment of intracranial aneurysms with preservation of the parent vessel: results of percutaneous balloon embolization in 84 patients. AJNR Am J Neuroradiol 1990;11(4):633-640

33 Higashida RT, Halbach VV, Hieshima GB, Weinstein PR, Hoyt WF. Treatment of a giant carotid ophthalmic artery aneurysm by intravascular balloon embolization therapy. Surg Neurol 1988; 30(5):382-386

34 Dowd CF, Halbach VV, Higashida RT, Barnwell SL, Hieshima GB. Endovascular coil embolization of unusual posterior inferior cerebellar artery aneurysms. Neurosurgery 1990;27(6):954-961

35 Guglielmi G, Viñuela F, Dion J, Duckwiler G. Electrothrombosis of saccular aneurysms via endovascular approach. Part 2: Preliminary clinical experience. J Neurosurg 1991;75(1):8-14

36 Litofsky NS, Viñuela F, Giannotta SL. Progressive visual loss after electrothrombosis treatment of a giant intracranial aneurysm: case report. Neurosurgery 1994;34(3):548-550; discussion 551

37 Katayama S, Fujita K, Takeda N, Okamura Y. Stent graft placement for the treatment of giant aneurysm at the proximal cavernous internal carotid artery. A case report. Interv Neuroradiol 2006;12 (Suppl 1):117-120

38 Drake CG, Peerless SJ, Ferguson GG. Hunterian proximal arterial occlusion for giant aneurysms of the carotid circulation. J Neurosurg 1994;81(5):656-665

39 Kothandaram P, Dawson BH, Kruyt RC. Carotid-ophthalmic aneurysms. A study of 19 patients. J Neurosurg 1971;34(4):544-548

40 Larson JJ, Tew JM Jr, Tomsick TA, van Loveren HR. Treatment of aneurysms of the internal carotid artery by intravascular balloon occlusion: long-term follow-up of 58 patients. Neurosurgery 1995;36(1):26-30; discussion 30

41 Nishioka H. Results of the treatment of intracranial aneurysms by occlusion of the carotid artery in the neck. J Neurosurg 1966;25(6): 660-704

42 Samson DS, Boone S. Extracranial-intracranial (EC-IC) arterial bypass: past performance and current concepts. Neurosurgery 1978;3(1):79-86

43 Streefkerk HJ, Wolfs JF, Sorteberg W, Sorteberg AG, Tulleken CA. The ELANA technique: constructing a high flow bypass using a non-occlusive anastomosis on the ICA and a conventional anastomosis on the SCA in the treatment of a fusiform giant basilar trunk aneurysm. Acta Neurochir (Wien) 2004;146(9):1009-1019; discussion 1019

44 Sorteberg W, Sorteberg A, Lindegaard KF, Boysen M, Nornes H. Transcranial Doppler ultrasonography-guided management of internal carotid artery closure. Neurosurgery 1999;45(1):76-87; discussion 87-88

45 Gelber BR, Sundt TM Jr. Treatment of intracavernous and giant carotid aneurysms by combined internal carotid ligation and extra- to intracranial bypass. J Neurosurg 1980;52(1): $1-10$

46 Serbinenko FA, Filatov JM, Spallone A, Tchurilov MV, Lazarev VA. Management of giant intracranial ICA aneurysms with combined extracranial-intracranial anastomosis and endovascular occlusion. J Neurosurg 1990;73(1):57-63

47 Romani R, Elsharkawy A, Laakso A, Kangasniemi M, Hernesniemi J. Tailored anterior clinoidectomy through the lateral supraorbital approach: experience with 82 consecutive patients. World Neurosurg 2012;77(3-4):512-517

48 Mattingly T, Kole MK, Nicolle D, Boulton M, Pelz D, Lownie SP. Visual outcomes for surgical treatment of large and giant carotid ophthalmic segment aneurysms: a case series utilizing retrograde suction decompression (the "Dallas technique"). J Neurosurg 2013;118(5):937-946 